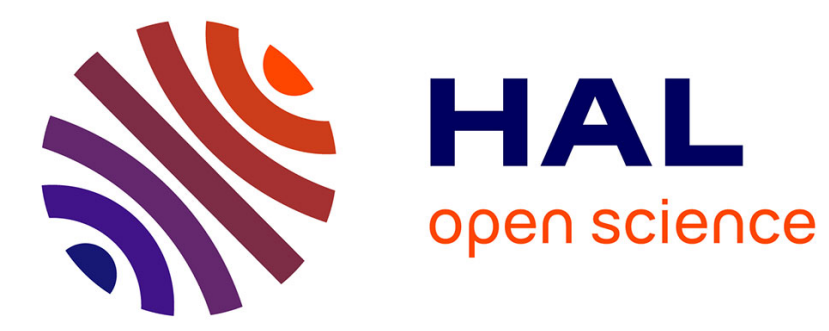

\title{
Leptin inhibits swallowing in rats
}

Bernadette Felix, André Jean, Claude Roman

\section{To cite this version:}

Bernadette Felix, André Jean, Claude Roman. Leptin inhibits swallowing in rats. AJP - Regulatory, Integrative and Comparative Physiology, 2006, 291 (3), pp.R657-R663. 10.1152/ajpregu.00560.2005 . hal-02655366

\section{HAL Id: hal-02655366 \\ https: / hal.inrae.fr/hal-02655366}

Submitted on 29 May 2020

HAL is a multi-disciplinary open access archive for the deposit and dissemination of scientific research documents, whether they are published or not. The documents may come from teaching and research institutions in France or abroad, or from public or private research centers.
L'archive ouverte pluridisciplinaire HAL, est destinée au dépôt et à la diffusion de documents scientifiques de niveau recherche, publiés ou non, émanant des établissements d'enseignement et de recherche français ou étrangers, des laboratoires publics ou privés. 


\section{Bernadette Félix, André Jean and Claude Roman}

Am J Physiol Regulatory Integrative Comp Physiol 291:657-663, 2006. First published Mar 30, 2006; doi:10.1152/ajpregu.00560.2005

You might find this additional information useful...

This article cites 42 articles, 14 of which you can access free at: http://ajpregu.physiology.org/cgi/content/full/291/3/R657\#BIBL

This article has been cited by 1 other HighWire hosted article:

BDNF-TrkB signaling interacts with the GABAergic system to inhibit rhythmic swallowing in the rat

B. Bariohay, C. Tardivel, J. Pio, A. Jean and B. Felix

Am J Physiol Regulatory Integrative Comp Physiol, October 1, 2008; 295 (4): R1050-R1059. [Abstract] [Full Text] [PDF]

Updated information and services including high-resolution figures, can be found at:

http://ajpregu.physiology.org/cgi/content/full/291/3/R657

Additional material and information about American Journal of Physiology - Regulatory, Integrative and Comparative Physiology can be found at:

http://www.the-aps.org/publications/ajpregu

This information is current as of September 7, 2010 .

The American Journal of Physiology - Regulatory, Integrative and Comparative Physiology publishes original investigations that illuminate normal or abnormal regulation and integration of physiological mechanisms at all levels of biological organization, ranging from molecules to humans, including clinical investigations. It is published 12 times a year (monthly) by the American

Physiological Society, 9650 Rockville Pike, Bethesda MD 20814-3991. Copyright @ 2006 by the American Physiological Society. ISSN: 0363-6119, ESSN: 1522-1490. Visit our website at http://www.the-aps.org/. 


\title{
Leptin inhibits swallowing in rats
}

\author{
Bernadette Félix, André Jean, and Claude Roman $\dagger$ \\ Université Paul Cézanne, Aix Marseille III, Faculté des Sciences et Techniques Campus St. Jérôme, \\ Laboratoire de Physiologie Neurovégétative, Unité Mixte de Recherche Physiologie Neuro Végétative \\ Centre National de la Recherche Scientifique-Institut National de la Recherche Agronomique- \\ Université, Institut Fédératif de Recherche Jean Roche, Marseille cedex 20, France
}

Submitted 29 July 2005; accepted in final form 18 March 2006

Félix, Bernadette, André Jean, and Claude Roman. Leptin inhibits swallowing in rats. Am J Physiol Regul Integr Comp Physiol 291: R657-R663, 2006. First published March 30, 2006; doi:10.1152/ajpregu.00560.2005.-Swallowing is under the control of premotoneurons located in the medullary solitary tract nucleus. Although rats with transected midbrain do not seek out food, they are able to ingest food present near the mouth, and acute food deprivation induces an increase in food intake. Leptin is a satiety signal that regulates feeding behavior. Because leptin receptors are found within the caudal brainstem, and because food intake is regulated in midbrain transected rats, this study tested the hypothesis that leptin is able to modify the activity of premotoneurons involved in swallowing. Leptin was microinjected at the subpostremal level of the medullary solitary tract nucleus in anesthetized Wistar rats. Electromyographic electrodes in sublingual muscles allowed recording of swallowing induced by stimulation of sensitive fibers of the superior laryngeal nerve. Repeated stimulation induced rhythmic swallowing. Microinjection of leptin $(0.1 \mathrm{pg}$ and $0.1 \mathrm{ng})$ in the swallowing center induced an inhibition of rhythmic swallowing (latency of $<30$ s) as shown by the reduced number and strength of electromyographic activities, which could last several minutes. The threshold of the leptin-induced inhibition was close to $0.1 \mathrm{pg}$. Interestingly, the inhibitory effect of leptin was not observed in leptin receptor-deficient Zucker rats. Here we show that, in Wistar rats, leptin already known to modulate the discharge of medullary solitary tract nucleus-sensitive neurons involved in satiety reflexes can also modify the activity of swallowing premotoneurons, thereby inhibiting an essential motor component of feeding behavior.

leptin; medullary solitary tract nucleus; swallowing; rat

SOLID OR LIQUID EDIBLE food may involve suckling, lapping, mastication, and in all cases swallowing. All of these functions are the motor components of ingestive behavior. The lower brainstem contains all the motoneurons regulating this behavior. During swallowing, the motoneurons are under the control of premotoneurons mainly located within the interstitial and intermediate subnuclei of the solitary tract nucleus (STN) that constitute the so-called "swallowing center" or "central pattern generator" (CPG) of swallowing (SwCPG; see Ref. 23). Although rats with transected midbrain do not seek out food, they will ingest food applied near the mouth, accepting or rejecting food by the taste (16). When they can be kept alive by careful tube feeding, acute food deprivation induces an increase in food intake $(17,18)$. Ingestive behavior in response to hypoglycemia also occurs in midbrain-transected rats (14).

Address for reprint requests and other correspondence: B. Felix, Université Paul Cézanne - Aix Marseille III, Faculté des Sciences et Techniques Campus St Jérôme, Laboratoire de Physiologie Neurovégétative, UMR PNV CNRSINRA-Université, IFR Jean Roche, Ave. Escadrille Normandie Niemen, 13397 Marseille cedex 20, France (e-mail: bernadette.felix@univ-cezanne.fr).

$\dagger$ Deceased, August 2005
The hindbrain contains: 1) several CPGs, the SwCPG but also mastication, suckling or lapping CPGs; 2) the corresponding motoneurons and the preganglionic neurons that control the gut movements, the pancreatic secretion, and the hepatic metabolism; 3) STN neurons that receive, during feeding, positive feedback from the mouth and negative feedback from the stomach, liver, and small intestine. The hindbrain is involved in what may be called the "direct control of eating" (39). In addition, in the intact animal, there are many reciprocal connections between the lower brain and the forebrain, especially the hypothalamus, limbic system, and frontal cortex, i.e., all the structures that are the sources of "indirect control of eating" (39).

Various neurotransmitter systems are involved in swallowing $(8,23)$. The main results concern induction and facilitation of CPG activity by excitatory amino acids (27), inhibition of the swallowing sequence by $\operatorname{GABA}(20,44)$, and the modulatory influence of monoamines (24). By contrast, little is known on the action of neuropeptides on the SwCPG, in particular on the role of peptides and neurohormones involved in food intake control.

Leptin, the product of the $o b$ gene (46), was first identified as a hormone, secreted by adipose tissue, that regulates feeding behavior and energy balance. It was recognized as a satiety signal that acts at the hypothalamic level $(11,21)$ and reduces body fat by reducing feeding and increasing the catabolic activity of the sympathetic system. It circulates in the blood at levels correlated with body fat mass, which may explain the term of lipostatic signal often employed. Circulating leptin reaches the brain through the choroid plexus by a receptormediated transport. Recent data reported that: 1) leptin receptors are found within the caudal brainstem, in the dorsal vagal complex, an area that includes the STN, the area postrema, and the dorsal motor nucleus of the vagus $(10,19) ; 2)$ microinjection of leptin $(1 \mu \mathrm{g})$ in the dorsal vagal complex suppresses food intake (19) measured at 2, 4, and $24 \mathrm{~h} ; 3$ ) leptin is also secreted from gastric mucosa (3), and this gastric leptin is able to increase the activity of STN neurons, the first relay station for vagal afferents $(45,37)$; and 4) gastric vagal afferent terminals (43) and vagal mechanosensitive fibers from the gastrointestinal tract (15) are responsive to leptin. Therefore, either gastric or adipocyte-derived leptin may act at the level of the STN, directly or via vagal fibers, as a satiety signal reducing food intake (2). Considering the above-mentioned food intake capabilities of mid-brain-transected rats, the question arises as to whether leptin acts uniquely as a signal modulating the discharge of sensitive neurons within the STN

\footnotetext{
The costs of publication of this article were defrayed in part by the payment of page charges. The article must therefore be hereby marked "advertisement" in accordance with 18 U.S.C. Section 1734 solely to indicate this fact.
} 
or if it is, in addition, able to modify directly the activity of STN premotoneurons involved in swallowing. The present work demonstrates that leptin microinjected directly in the interstitial and intermediate STN subnuclei inhibits swallowing, an essential motor component of ingestive behavior, and so participates in the control of food intake and body weight homeostasis.

\section{METHODS}

The experimental procedures described here were carried out in accordance with the European guidelines for the care and use of laboratory animals (Council Directive 86/6009/EEC) and the French law on the Protection of Animals (1987; revised 2001).

Surgical procedures. Experiments were performed on 35 adult Wistar rats weighing from 200 to $350 \mathrm{~g}$, and 12 Zucker rats (6 rats falfa weighing from 500 to $560 \mathrm{~g}$ and 6 rats $f a l+$ weighing from 400 to $440 \mathrm{~g}$; Charles River, l'Arbresle, France) anesthetized with a mixture of ketamine $(100 \mathrm{mg} / \mathrm{ml})$ and xylazine $(15 \mathrm{mg} / \mathrm{ml}$; Centravet, Dinan, France) in a proportion of $90 \%$ and $10 \%$, respectively. The anesthesia was then continued by perfusion of the same mixture through a catheter inserted in the peritoneal cavity, at a rate of $0.5-1$ $\mathrm{ml} / \mathrm{h}$. Each superior laryngeal nerve (SLN) was dissected free from surrounding tissues and placed on miniature bipolar electrodes. Animals were then fixed in a stereotaxic frame (Horsley and Clarke apparatus adapted for rats) in such a position that, after occipitoparietal craniotomy and removal of the posterior part of the cerebellum, the floor of the fourth ventricle appeared to lie in a horizontal plane. Its surface was covered with warm liquid paraffin.

Stimulations and recordings. Swallowing was triggered by stimulation of the sensitive fibers contained in the SLN. Stimulation with a short train of pulses induced a single swallowing, whereas stimulation with a long train of pulses produced several swallows [or rhythmic swallowing recorded by electromyography (EMG)], at a rhythm depending on stimulation frequency (Fig. 1). In the present study, only long trains of pulses ( $3-5 \mathrm{~s}$ duration; $10-30 \mathrm{~Hz}$ frequency) were used. The pulse voltage and duration varied according to the animal (1-3 volts; $0.05-0.5 \mathrm{~ms})$. During these stimulations, the respiration was more or less completely blocked (Fig. 1).

To monitor swallowing, the EMG activity of sublingual muscles (mainly the geniohyoid) was recorded by means of bipolar copper wire electrodes, insulated except at the tip, and inserted in the muscles (7). In a first series of experiments, the EMG signals, suitably amplified, were displayed on an oscilloscope (Tektronix 5111) and stored on a computer using pCLAMP 6.0.1 software (Axon Instru-
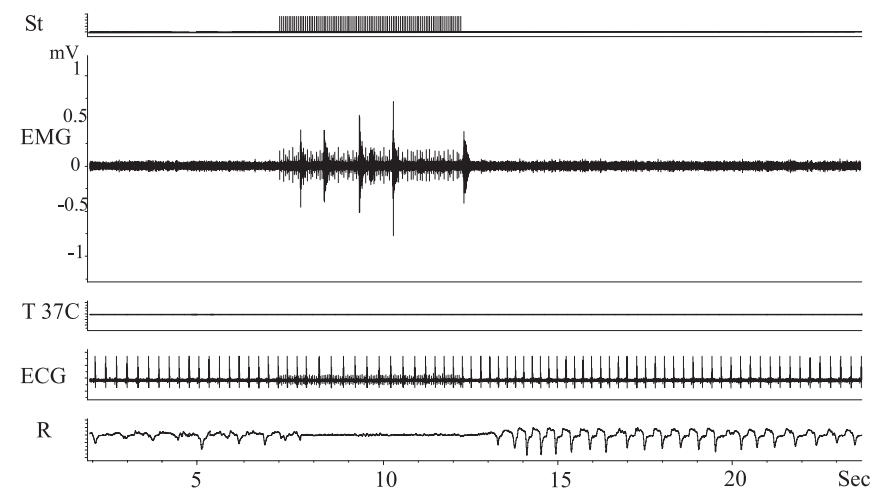

Fig. 1. Example of polygraphic recording. St, stimulation of SLN at 20 pulses/s during $5 \mathrm{~s}$ (pulse parameters, 1.5 volts and $0.2 \mathrm{~ms}$ ); EMG, electromyogram from genioglossus muscle. Note the rhythmic swallowing triggered by superior laryngeal nerve (SLN) stimulation; T, rectal temperature in ${ }^{\circ} \mathrm{C}$; ECG, electrocardiogram; R, respiration. Note the respiration blockade during the stimulation inducing rhythmic swallowing. ments, Foster City, CA). In a second series, we had at our disposal a PowerLab data acquisition system with eight input channels connected to a personal computer, with chart software for Windows (record, display, store, analyze). Body temperature was recorded continuously by a rectal thermal probe and was maintained at 36$37^{\circ} \mathrm{C}$ by means of a warming device. Electrocardiogram (ECG) picked up by subcutaneous electrodes on each side of the thorax, and respiratory activity recorded by a mechanotransducer (or a thermistance in front of the nose) allowed heart rate (ECG) and respiration monitoring, respectively (see Fig. 1). Electrocardiogram and swallowing EMG fed loud speakers for auditory control.

Microinjections. Pressure ejections of drug solutions were performed, either directly through a Hamilton syringe allowing the injection of $50-100 \mathrm{nl}$ or via glass pipettes $(70-100 \mu \mathrm{m}$ OD at the tip) using a pneumatic pressure system (Neurophore BH2; Medical System, Great Neck, NY). The following agents, obtained from Sigma, were used: $6 \times 10^{-9}$ to $6 \times 10^{-12} \mathrm{M}$ leptin, $10^{-3}$ to $10^{-9} \mathrm{M}$ L-glutamic acid, and $10^{-3} \mathrm{M} \gamma$-aminobutyric acid (GABA). All of these drugs were dissolved in a $0.9 \% \mathrm{NaCl}$ solution. In a first series of experiments, high doses of leptin were used to search for a possible effect of the drug. Next, lower doses were used to determine the threshold of leptin-induced action.

Recombinant rat leptin was first dissolved in $1 \mathrm{ml}$ distilled water. The solution was diluted in PBS, separated into aliquots, and stored at $-70^{\circ} \mathrm{C}$. One aliquot $(1 \mu \mathrm{l})$ was used for each experiment.

The maximum volume ejected through the micropipette was 50 or more frequently $100 \mathrm{nl}$ (amount measured with the Hamilton syringe used to inject the drug in the glass pipette). For pressure ejection, the volume was checked under a microscope, and the parameters (between 80 and $150 \mathrm{kPa}$ for pulses of $1-5 \mathrm{~s}$ duration) were adjusted to obtain $100 \mathrm{nl}$ of leptin colored by addition of pontamine blue in a droplet of paraffin oil. Therefore, the maximum amount injected in the structure was $0.1 \mathrm{pg}$ or $0.1 \mathrm{ng}$.

Histological controls. In 20 experiments, pontamine blue (4\%) was added to the drug solution injected. It had previously been checked that this dye alone produced no effect on swallowing. At the end of these experiments, the brainstem was removed and placed in a solution of $4 \%$ formaldehyde. Frontal frozen sections (30-50 $\mu \mathrm{m}$ thick) were cut and examined for histological localization of the injection site.

Experimental procedures. We studied how various agents [leptin, glutamate (swallowing agonist), GABA (swallowing antagonist), and vehicle of drugs alone $(0.9 \% \mathrm{NaCl})$ ] affect the rhythmic swallowing elicited by long repetitive stimulations of the SLN. The drugs were microinjected stereotaxically in the SwCPG, located in the region of STN extending between 0.5 and $0.7 \mathrm{~mm}$ rostral to the caudal edge of the area postrema (taken as the 0 ), $0.6-0.8 \mathrm{~mm}$ laterally, and $0.6-0.8$ $\mathrm{mm}$ in depth. These coordinates correspond to those given by Kessler et al. (25-27) for rats of similar weight. In addition, glutamate was also tested in the absence of SLN stimulation to check whether the drug triggered swallowing when the micropipette was positioned according to the above-mentioned coordinates.

After the positioning of the micropipette in the injection site, stimulation trains of pulses were delivered to the ipsilateral SLN every $30 \mathrm{~s}$. A control episode including at least five trains of stimulations was performed before drug injection. Next, stimulation and recording were maintained until recovery.

Statistical analysis. Cardiac and respiration frequencies were expressed as means \pm SE. Data were analyzed using ANOVA, followed by Fischer's protected least-significant difference test. Statistical analysis software (StatView for windows 5.0.1; SAS Institute) was used. The criterion for significance was $P<0.05$.

\section{RESULTS}

Checking the localization of the SwCPG. To check that the stereotaxic coordinates used in these experiments corresponded to those of the SwCPG, we have shown that, in accordance 
with previous demonstration (26), microinjection of glutamate within this site can initiate swallowing (Fig. 2A), as does SLN stimulation. The effects of microinjections of leptin were tested at the same site. In addition, we controlled that GABA injected at this site (Fig. $2 B$ ) induced an inhibition of swallowing (8, $44)$. In some experiments $(n=12)$, we injected, at the same site, glutamate and then leptin. The coronal section of Fig. $2 C$ indicates the area within which all injections of drugs were made.

Effects of leptin microinjections in the SwCPG. In 51 trials performed on 31 Wistar rats, microinjections of leptin, either at low (13 rats) or high doses (18 rats), always resulted in an inhibition of rhythmic swallowing (Fig. 3). The effect occurred with a very brief latency (Fig. $3 A$ ). Indeed, the number of swallows usually decreased as soon as the first train of stimulating pulses after microinjection. Considering that stimulations were repeated every $30 \mathrm{~s}$, and that injection was made between two of them, it can be deduced that the latency was $<30$ s. The duration and intensity of this inhibition varied according to the doses of leptin injected. At the lowest doses $\left(0.1 \mathrm{pg}\right.$ or $\left.6 \times 10^{-12} \mathrm{M}\right)$, inhibition lasted 5-7 $\mathrm{min}$ at the most and only occasionally resulted in a total suppression of rhythmic swallowing (Fig. 3Al). At higher doses $(0.1 \mathrm{ng}$ or $6 \times$ $10^{-9} \mathrm{M}$ ), the effects were more pronounced; not only did rhythmic swallowing usually disappear, but also, the duration of the inhibition ranged from $<15 \mathrm{~min}$ up to $1 \mathrm{~h}$ and more. Partial recovery was only obtained in a few experiments when higher doses were used. One example is shown in Fig. 3B. The intensity of inhibition could be evaluated according to the following two criteria: number of swallows per pulse train and strength of individual swallowing contractions before the total disappearance (when occurring). As indicated above, we always observed a decrease in the number of swallows (Fig. 4), and very frequently their disappearance. The decrease in the number of swallows was accompanied by a reduction in the intensity of the global swallowing EMG, more especially visible when the inhibition was powerful (Fig. 3B). The inhibitory effect of leptin was similar to that obtained with GABA microinjection. It is worth noting, however, that recovery was more rapid after GABA injection than after leptin application (Fig. 4).

During the inhibitory action of leptin, and particularly when rhythmic swallowing disappeared, a further increase in stimulation parameters allowed the swallows to reappear or to increase in number (Fig. 3B), indicating that the SwCPG excitability had been reduced, with an increase of its triggering threshold. This result was not because of lesions of afferent fibers or changes in electrode impedance, since, after recovery, the stimulation parameters for obtaining control rhythmic swallowing returned to initial values.

As for cardiac and respiratory rhythms, no changes were observed under the action of leptin (Fig. 4). The well-known inhibition of respiration (9) during swallowing afferent stimulation also persisted (Fig. 1).

Control experiments. Intramedullary microinjections of $0.9 \% \mathrm{NaCl}$ or pontamine blue solutions (trials on 3 different rats) caused no effect on rhythmic swallowing, even after several applications. It was also worth noting that the inhibitory effect of leptin was observed only when the ipsilateral SLN was stimulated. Stimulation of the contralateral SLN still induced swallowing (data not shown).

To evaluate the specificity of the effect of leptin, a series of microinjections was performed on genetically obese Zucker rats, with the lowest doses of leptin $(0.1 \mathrm{pg})$ that range within the physiological concentrations (see DISCUSSION). No modification of swallowing activity was observed when leptin was microinjected in STN of homozygous rats ( $f a / f a$; Fig. 5, $A$ and $C)$. Interestingly, within the same sites, GABA microinjection $\left(10^{-3} \mathrm{M}\right)$ still induced clear-cut inhibition of swallowing (Fig. $5 B$ ). A slight but not significant decrease of swallowing number was obtained when leptin microinjections were performed in heterozygous $(\mathrm{fa} /+)$ Zucker rats (Fig. 5C).
A
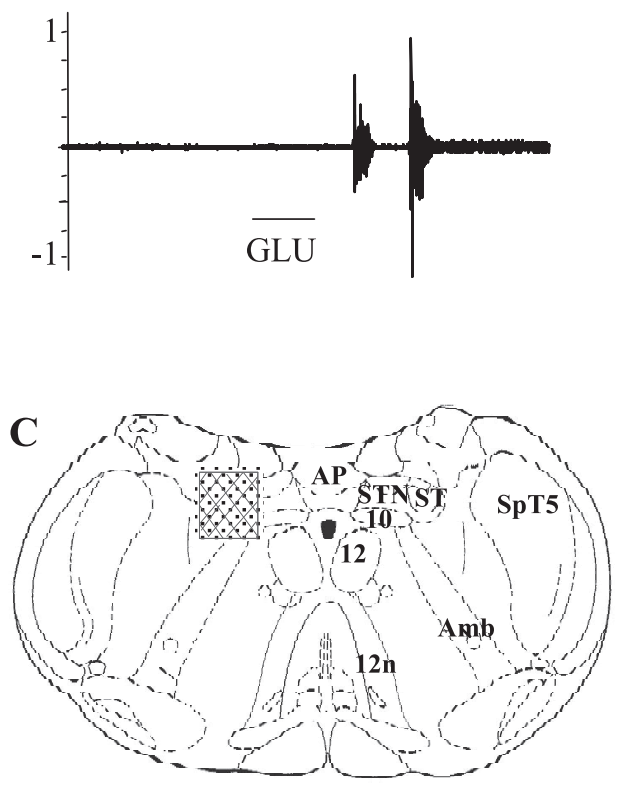

B
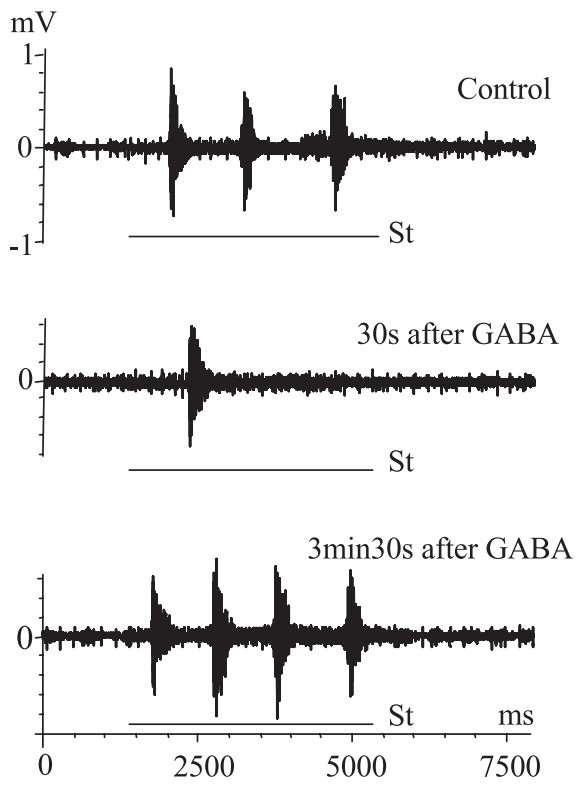

Fig. 2. Localization of the central pattern generator of swallowing (SwCPG). The 2 experiments in $A$ and $B$ were carried out on 2 different rats. The coronal diagram of the medulla in $C$, drawn from the atlas of Paxinos and Watson (35a), corresponds to the level of the injection sites of glutamate, $\gamma$-aminobutyric acid (GABA), and leptin (between 0.5 and $0.7 \mathrm{~mm}$ in front of the caudal edge of the area postrema). Although microinjections were made on both sides of the medulla, all sites of injections have been reported to the left side and are gathered in the hatched area corresponding to the region of the interstitial and intermediate solitary tract nucleus (STN) subnuclei. Amb, ambiguus nucleus; AP, area postrema; SpT5, spinal trigeminal tract; ST, solitary tract; 10, dorsal motor nucleus of the vagus; 12 , hypoglossal nucleus; $12 \mathrm{n}$, roots of hypoglossal nerve. A: microinjection of glutamate (GLU, $10^{-6} \mathrm{M} ; 1$ pressure pulse); 2 swallows were triggered. $B$ : effect of microinjection of GABA $\left(10^{-3} \mathrm{M} ; 1\right.$ pressure pulse) on rhythmic swallowing. SLN repetitive stimulation (St, 5 volts, $0.06 \mathrm{~ms}, 15 \mathrm{~Hz}$ during $4 \mathrm{~s}$ ). Note the inhibition of rhythmic swallowing after GABA injection and the recovery with a rebound effect. 
A1
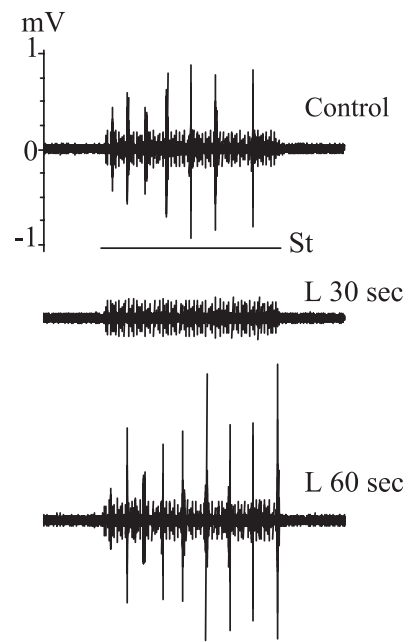

rhythmic swallowing triggered by SLN stimulation; effects of the doses. Tracings in $A$ and $B$, obtained from 2 different animals, should be read from top to bottom. The leptin concentration was $0.1 \mathrm{pg}$ for $A 1$ and $A 2$ and $0.1 \mathrm{ng}$ for $B$. Stimulation parameters in $A 1$ and $A 2$ were 5 volts, $0.2 \mathrm{~ms}, 20$ $\mathrm{Hz}$ during $5 \mathrm{~s}$. Note in $A 1$ the complete and very short inhibition of rhythmic swallowing and, in $A 2$, the less important inhibition and the slightly longer recovery. In $B$, the stimulation voltage was different, as shown on the tracings. For the first (control) and the last (recovery) tracings, the parameters were as follows: 1.5 volts, $0.08 \mathrm{~ms}, 30 \mathrm{~Hz}$ during $3 \mathrm{~s}$. For all tracings, the voltage is indicated under the trace, with the other parameters remaining identical. Note 1 ) that the inhibition of rhythmic swallowing was powerful (disappearance of the response) and long-lasting (recovery after $125 \mathrm{~min}$ ) and 2) that, during maximum inhibition, between 40 and 60 $\mathrm{min}$, the increase in voltage stimulation was allowed to obtain a rhythmic swallowing very similar to that of control, indicating that during this period the swallowing CPG was less excitable but nevertheless able to function. L $30 \mathrm{sec}$ to L 125 min indicates the time after leptin injection.

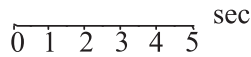

St

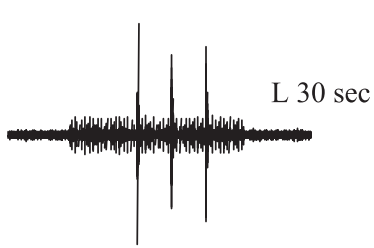

\section{DISCUSSION}

This study showed that leptin inhibits swallowing, a fundamental component of food intake. This result is congruent with the well-documented action of leptin on ingestion $(2,5,6,12$, 13). What was new, however, is the fact that this adiposity signal, strongly involved in satiety, was able to act not only on the afferent and integrative system of feeding but also on the motor component of this system. This is probably one explanation for the capacity for food intake regulation in the midbrain-transected animals (18).

Within the brainstem site studies, the leptin-induced effect on swallowing appears to be specific, since inhibition was
B

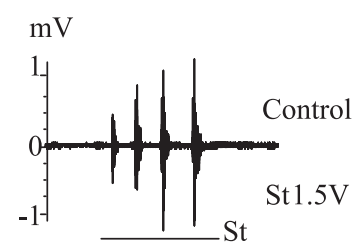

St

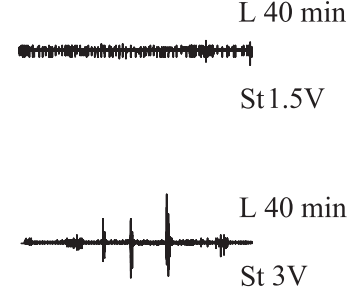

St 3V

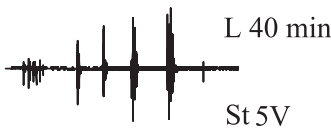

L $60 \mathrm{sec}$
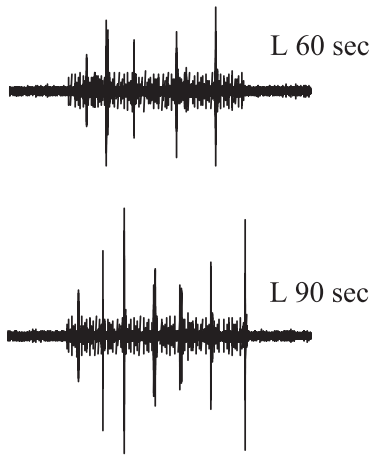

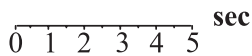

never observed with $0.9 \% \mathrm{NaCl}$ or pontamine blue solutions, and leptin had no effect on heart rate and respiratory rhythm. In addition, in the leptin receptor-deficient rat Zucker, leptin did not modify swallowing activity, whereas GABA still induced an inhibitory effect.

The fact that leptin was injected within the SwCPG area could be attested by the following evidence: 1) microinjections of transmitters (glutamate and GABA) known to be involved in swallowing activation or inhibition, respectively $(23,25,20)$, gave the expected responses; 2$)$ in the experiments where injections of glutamate and leptin were made successively at the same point, the results were those ex- 


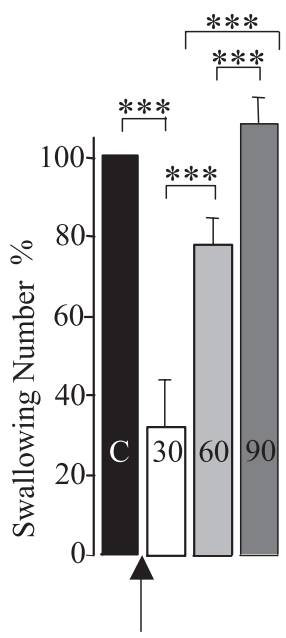

GABA

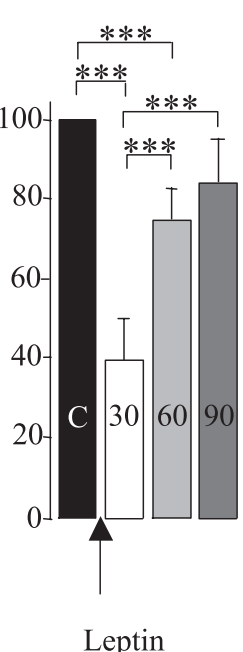

Leptin

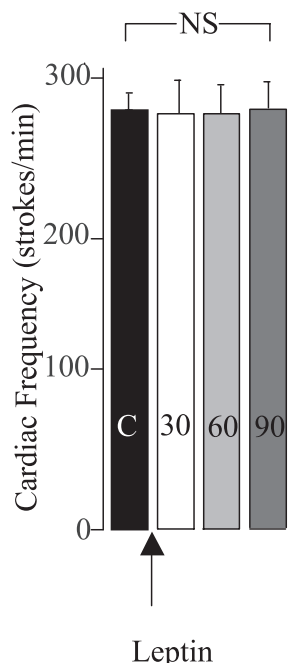

Leptin

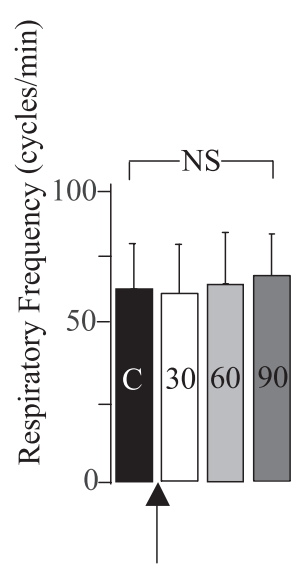

Leptin
Fig. 4. Effects on swallowing of leptin and GABA microinjections in the medullary STN. Each bar represents the percentage of the nos. of rhythmic swallowing or mean frequencies of cardiac or respiratory rhythms during a period of time of $30 \mathrm{~s}$ before [control (C)] and after $(30,60,90 \mathrm{~s})$ injections of 0.1 pg of leptin (L) or GABA $\left(10^{-3} \mathrm{M}\right)$, indicated by arrows. Leptin and GABA significantly inhibit rhythmic swallowing triggered by SLN stimulation $(* * * P<0.001)$. Note a more rapid recovery after GABA than after leptin injection. In addition, it could be noted that no significant difference (NS) in the frequencies of cardiac and respiratory rhythms were observed. pected (excitation and inhibition, respectively); and 3) the latency of leptin effect was very short $(<30 \mathrm{~s})$, indicating that the drug must have been injected very close to the neurons of the SwCPG.
Variations in leptin effects could be explained by the quantity of drug injected $(0.1 \mathrm{pg}$ or $0.1 \mathrm{ng})$. The major difference between the two doses concerned the duration of the effects obtained, which is easy to understand since it was with the
A
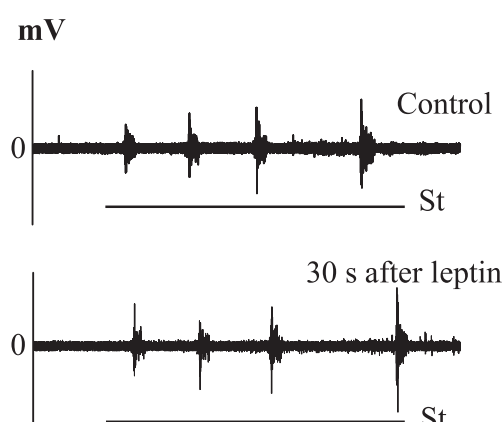

St
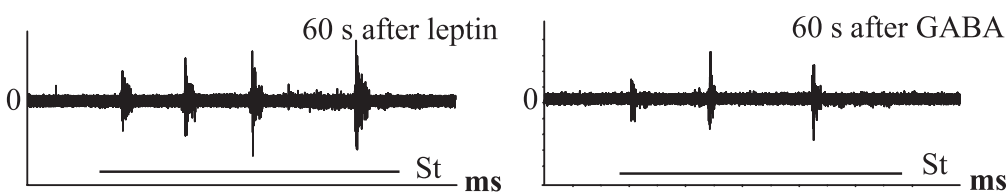

C

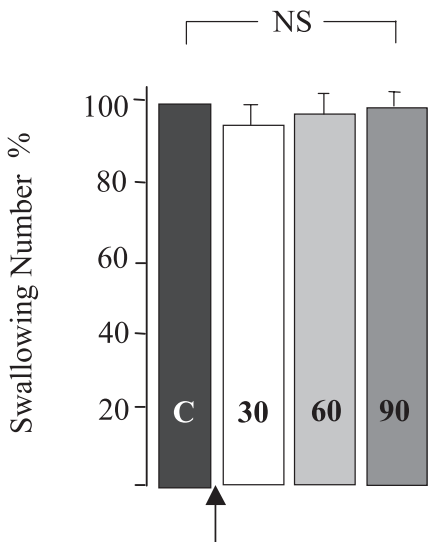

Leptin

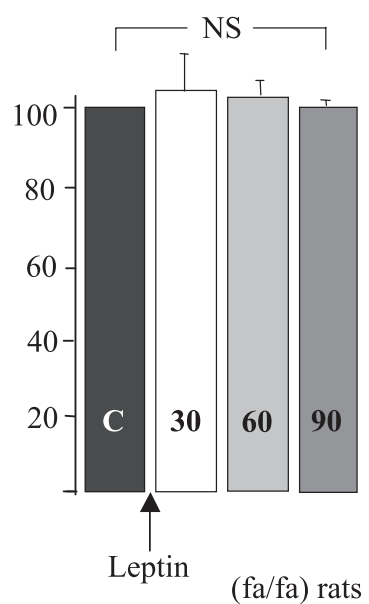

\section{B}

$\mathbf{m V}$

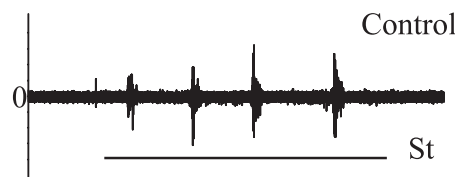

$30 \mathrm{~s}$ after GABA

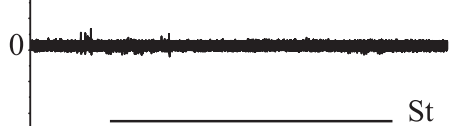

$\mathrm{St}$

Fig. 5. Effect of leptin and GABA microinjections within the medullary STN of genetically obese Zucker rats. Effect of leptin $(A)$ and GABA $(B)$ microinjections performed within the same site of homozygous $(f a / f a)$ Zucker rats. Note the typical inhibitory effect of GABA $\left(10^{-3} \mathrm{M}\right)$, whereas leptin administration induced no modification in rhythmic swallowing. $C$ : effect of leptin microinjections in heterozygous $(f a /+; n=19)$ and homozygous ( $f a / f a$; $n=17$ ) Zucker rats. Each bar represents the percentage of the nos. of rhythmic swallowing during a period of time of $30 \mathrm{~s}$ before (C) and after injection $(30,60,90 \mathrm{~s})$ of $0.1 \mathrm{pg}$ of leptin, indicated by arrows. 
higher dosage that the duration of the inhibition showed greater variability. Blood leptin concentrations in normal rats are in the range of $2-10 \mathrm{ng} / \mathrm{ml}(0.1-0.6 \mathrm{nM}$; see Refs. 1 and 41), with an increase of $\sim 2 \mathrm{ng} / \mathrm{ml}(0.1 \mathrm{nM})$ after feeding. Leptin can readily cross the blood-brain and blood-cerebrospinal fluid (CSF) barriers to reach the central nervous system $(4,29)$, but the mechanisms of this transfer are still a matter of debate, although it seems to be acknowledged that high-affinity transport systems, some being saturable, are involved $(4,29)$. Some reports in humans $(28,31)$ and sheep $(42)$ mention that the amount of leptin in the CSF is lower than that in the blood, with the CSF-to-plasma leptin ratio being near 0.025. If this ratio is of same magnitude in the rat, the maximum CSF leptin concentration should be in the range of $0.05-0.25 \mathrm{ng} / \mathrm{ml}(2.5 \times$ $10^{-11}$ to $\left.1.5 \times 10^{-12} \mathrm{M}\right)$. The lowest doses employed in our experiments $\left(6 \times 10^{-12} \mathrm{M}\right)$ are very close to these values and so fall within the physiological range. On the contrary, the highest doses $\left(6 \times 10^{-9} \mathrm{M}\right)$ used in the initial experiments for detecting a possible action of leptin belong to the pharmacological domain. It must be emphasized that, in works using the patch-clamp technique on hypothalamic slices, leptin is currently perfused at $10^{-6}$ to $10^{-11} \mathrm{M}(30,36,38,40)$.

Leptin receptors are abundant in the lower brain, and particularly in the dorsal vagal complex, which includes the STN $(18,22)$. Numerous data gathered over 30 years in the laboratory have demonstrated that the interstitial and intermediate STN subnuclei are an essential part of the SwCPG, i.e., the one that programs the entire motor sequence of swallowing (23, 27). It is thus tempting to assume that leptin decreases the excitability of this programming system, which is able to function rhythmically when solicited by repetitive afferent stimulations (rhythmic swallowing). Our study does not allow us to demonstrate the mechanism of leptin action that might consist in postsynaptic inhibition of the neurons themselves or presynaptic inhibition of excitatory afferent fibers. However, in the medial part of the arcuate nucleus of the hypothalamus slices from Wistar rats, it was shown that leptin inhibited $\sim 60 \%$ of neurons through a direct postsynaptic action (32). In addition, some works indicate that the inhibitory action of leptin may involve GABA (35).

The inhibitory action of leptin on the STN premotoneurons reported in this study is not in accordance with that described by other authors who worked on the sensitive neurons of the STN, relaying the vagal fibers issued from the stomach (37). Those authors observed a facilitation of neuronal discharge evoked by stomach loading, which is in keeping with the satiating role of stomach distension and of leptin injection. Yet, it cannot be taken for granted that all of the STN neurons behave in the same way. Some visceral afferent fibers of the vagus nerve, having a role in satiation, decrease firing when satiety occurs. It is the case, for example, of the glucosensitive fibers coming from the liver, which stop firing when glucose is infused in the portal vein $(33,34)$. It has been shown that the resting discharge of such glucose-sensitive fibers was inhibited by peripherally acting leptin (38). It is reasonable to envisage that the STN neurons connected to these fibers should also be inhibited by circulating leptin. In fact, the mode of action of leptin, like that of many other transmitters, probably varies according to the functional context or purpose.

In conclusion, our results show that leptin at physiological doses inhibits the SwCPG in anesthetized rats and conse- quently the activity of the motoneurons involved in swallowing. Because this motor activity has a major role in ingestion, it can therefore be inferred that leptin inhibits ingestion by acting not only on the afferent and integrative components of the feeding nervous system but also on its motor outputs.

\section{ACKNOWLEDGMENTS}

We thank Jérôme Espejo for taking care of the animals, Juliette Pio for providing histological and technical assistance, Jean-Pierre Roman for designing the electronic devices, and Catherine Tardivel and Kathleen Horner for revising the English.

This work was presented during a poster session at the Fédération Européenne des NeuroSciences meeting of Lisbon, July 10-14, 2004 (abstract 2: AO94-5).

\section{GRANTS}

This work was supported by funds from the National Center of Scientific Research, the National Institute of Agronomic Research, the University, Région Provence Alpes Côte d'Azur, and Conseil Général 13.

\section{REFERENCES}

1. Asakuma S, Hiraku O, Kurose Y, Kobayashi S, and Terashima Y. Diurnal rhythm of cerebrospinalfluid and plasma leptin levels relate feeding in non-lactating and lactating rats. J Endocrinol 180: 283-286, 2004.

2. Attele AS, Shi ZQ, and Yuan CS. Leptin, gut, and food intake. Biochem Pharmacol 63: 1579-1583, 2002.

3. Bado A, Levasseur S, Attoub S, Kermorgant S, Laigneau JP, Bortoluzzi MN, Moizo L, Lehy T, Guerre-Millo M, Le Marchand-Brustel Y, and Lewin MJM. The stomach is a source of leptin. Nature 394: 790-793, 1998.

4. Banks WA. The many lives of leptin. Peptides 25: 331-338, 2004

5. Baskin DG, Blevins JE, and Schwartz MW. How the brain regulates food intake and body weight: the role of leptin. J Pediatr Endocrinol Metab 14: 1417-1429, 2001.

6. Baskin DG, Figlewicz LD, Seeley RG, Woods SC, Porte D, and Schwartz MW. Insulin and leptin: dual adiposity signals to the brain for the regulation of food intake and body weight. Brain Res 848: 114-123, 1999.

7. Basmajian JV and Steko G. A new bipolar electrode for electromyography (Abstract). J Appl Physiol 17: 849, 1962.

8. Bieger D. Central nervous system control mechanism of swallowing: a neuropharmacological perspective. Dysphagia 8: 308-310, 1993.

9. Doty RW. Neural organization of deglutition. In: Handbook of Physiology. Alimentary Canal. Washington, DC: Am Physiol Soc, 1968, vol. IV, sect. VI, p. 1861-1902.

10. Elmquist JK, Bjorbaek C, Ahima RS, Flier JS, and Saper CB. Distributions of leptin receptor mRNA isoforms in the rat brain. J Comp Neurol 395: 535-547, 1998.

11. Elmquist JK, Elias CF, and Saper CB. From lesions to leptin: hypothalamic control of food intake and body weight. Neuron 22: 221-232, 1999.

12. EImquist JK and Flier JS. Neuroscience. The fat-brain axis enters a new dimension. Science 304: 63-64, 2004.

13. Emond M, Ladenheim EE, Schwartz GJ, and Moran TH. Leptin amplifies the feeding inhibition and neural activation arising from a gastric nutrient preload. Physiol Behav 72: 123-128, 2001.

14. Flynn FW and Grill HG. Insulin elicits ingestion in decerebrate rats. Science 221: 188-189, 1983.

15. Gaigé S, Abysique A, and Bouvier M. Effects of leptin on cat intestinal vagal mechanoreceptors. J Physiol (Lond) 543: 679-689, 2002.

16. Grill HJ and Norgren R. The taste reactivity test. II. Mimetic responses to gustatory stimuli in chronic thalamic and chronic decerebrate rats. Brain Res 143: 281-297, 1978.

17. Grill HJ and Kaplan JM. Caudal brainstem participates in the distributed neural control of feeding. In: Handbook of Behavioral Neurobiology: Neurobiology of Food and Fluid Intake, edited by Stricker EM. New York: Plenum, 1990, vol. 10, p. 125-149.

18. Grill HJ and Kaplan JM. Sham feeding in intact and decerebrate rats. Am J Physiol Regul Integr Comp Physiol 262: R1070-R1074, 1992. 
19. Grill HJ, Schwartz MW, Kaplan JM, Foxhall JS, Breininger J, and Baskin DG. Evidence that the caudal brainstem is a target for the inhibitory effect of leptin on food intake. Endocrinology 143: 239-246, 2002.

20. Harada H, Takakusaki K, Kita S, Matsuda M, Nonaka S, and Sakamoto T. Effects of injecting GABAergic agents into the medullary reticular formation upon swallowing induced by the superior laryngeal nerve stimulation in decerebrate cats. Neurosci Res 51: 395-404, 2005.

21. Hillebrand JJG, de Wied D, and Adan RAH. Neuropeptides, food intake and body weight regulation: a hypothalamic focus. Peptides 23: 2283-2306, 2002.

22. Hosoi T, Kawagishi T, Okuma Y, Tanaka J, and Nomura Y. Brain stem is a direct target for leptin's action in the central nervous system. Endocrinology 143: 3498-3504, 2002.

23. Jean A. Brain stem control of swallowing: neural network and cellular mechanisms. Physiol Rev 81: 929-969, 2001.

24. Jean A, Kessler JP, and Tell F. Nucleus tractus solitarii and deglutition: monoamines, excitatory amino acids and cellular properties. In: Nucleus of the Solitary Tract, edited by Baracco RA. Boca Raton, FL: CRC, 1994, p. 361-375.

25. Kessler JP, Cherkaoui N, Catalin D, and Jean A. Swallowing responses induced by microinjections of glutamate and glutamate agonists into the nucleus tractus solitarius of ketamine anaesthetized rats. Exp Brain Res 83: 151-158, 1990.

26. Kessler JP and Jean A. Identification of the medullary swallowing regions in the rat. Exp Brain Res 57: 256-263, 1985.

27. Kessler JP and Jean A. Evidence that activation of $N$-methyl-D-aspartate (NMDA) and non-NMDA receptors within the nucleus tractus solitarii triggers swallowing. Eur J Pharmacol 201: 59-67, 1991.

28. Koistinen HA, Karonen SL, Iivanen M, and Koivisto VA. Circulating leptin has saturable transport into intrathecal space in humans. Eur J Clin Invest 28: 894-897, 1998.

29. Kurrimbux D, Gaffen Z, Farrell CL, Martin D, and Thomas SA. The involvement of the blood-brain and the blood-cerebrospinal fluid barriers in the distribution of leptin into and out of the rat brain. Neuroscience 123: 527-536, 2004.

30. Lee $\mathbf{J}$ and Morris MJ. Modulation of neuropeptideY overflow by leptin in the rat hypothalamus, cerebral cortex and medulla. Neuroreport 9: 1575-1580, 1998.

31. Mantzoros C, Flier JS, Lesem MD, Brewerton TD, and Jimerson DC. Cerebrospinal fluid leptin in anorexia nervosa: correlation with nutritional status and potential role in resistance to weight gain. J Clin Endocrinol Metab 82: 1845-1851, 1997.

32. Nagamori K, Ishibashi M, Shiraishi T, Oomura Y, and Sasaki K. Effetcs of leptin on hypothalamic arcuate neurons in Wistar and Zucker rats: an in vitro study. Exp Biol Med 228: 1162-1167, 2003.
33. Niijima A. Afferent impulse discharges from glucoreceptors in the liver of the guinea pig. Ann NY Acad Sci 157: 690-700, 1969.

34. Niijima A. Glucose-sensitive afferent nerve fibers in the liver and their role in food intake and blood glucose regulation. J Auton Nerv Syst 9: 207-220, 1983.

35. Ovesjo ML, Gamstedt M, Collin M, and Meister B. GABAergic nature of hypothalamic leptin target neurones in the ventromedial arcuate nucleus. J Neuroendoc 13: 505-516, 2001.

35a.Paxinos G and Watson C. The Rat Brain Stereotaxic Coordinates (4th ed.). San Diego, CA: Academic, 1998.

36. Saleri R, Giustina A, Tamanini C, Valle D, Burattin A, Wehrenberg WB, and Baratta M. Leptin stimulates grow hormone secretion via a direct pituitary effect combined with a decreased somatostatin tone in a median eminence-pituitary study. Neuroendocrinology 79: 221-228, 2004.

37. Schwartz GJ and Moran TH. Leptin and Neuropeptide Y have opposing modulatory effects on the nucleus of the solitary tract neurophysiological responses to gastric loads: implications for the control of food intake. Endocrinology 143: 3779-3784, 2002.

38. Shiraishi T, Sasaki K, Niijima A, and Oomura Y. Leptin effects on feeding-related hypothalamic and peripheral neuronal activities in normal and obese rats. Nutrition 15: 576-579, 1999.

39. Smith GP. The controls of eating: a shift from nutritional homeostasis to behavioral neuroscience. Nutrition 16: 814-820, 2000.

40. Spanswick D, Smith MA, Groppi VE, Logan SD, and Ashford MLJ. Leptin inhibits hypothalamic neurons by activation ATP-sensitive potassium channels (Abstract). Nature 390: 521, 1997.

41. Tanaka M, Nakaya S, Kumai T, Watanabe M, Tateihi T, Shimizu H, and Kobayashi S. Effects of oestrogen on serum leptin levels and leptin mRNA expression by adipose tissue in rats. Horm Res 56: 98-104, 2001.

42. Thomas SA, Preston JE, Wilson MR, Farell CL, and Segal MB. Leptin transport at the blood-cerebrospinal fluid barrier using the perfused sheep choroid plexus model. Brain Res 895: 283-290, 2001.

43. Wang YH, Taché Y, Sheibel AB, Go VLW, and Wei JY. Two types of leptin-responsive gastric vagal afferent terminals: an in vitro single-unit study in rats. Am J Physiol Regul Integr Comp Physiol 273: R833-R837, 1997.

44. Wang YT and Bieger D. Role of solitarial GABAergic mechanism in control of swallowing. Am J Physiol Regul Integr Comp Physiol 267: R639-R646, 1994.

45. Yuan CS, Attele AS, Wu JA, Zhang L, and Shi ZQ. Peripheral gastric leptin modulates brain stem neuronal activity in neonates. Am J Physiol Gastrointest Liver Physiol 277: G626-G630, 1999.

46. Zhang Y, Proenca R, Maffei M, Barone M, Leopold L, and Friedman JM. Positional cloning of the mouse obese gene and its human homologue. Nature 372: 425-432, 1994. 